\section{Dealing with the neglected public health issue of drowning in low-resource settings}

Sir,

Globally, drowning has been acknowledged as one of the leading causes of deaths attributed to unintentional injury and accounts for almost $9 \%$ of all injury-related fatalities. ${ }^{[1]}$ The current estimates suggest that every year almost 0.37 million people die due to drowning, of which more than $90 \%$ of the victims are from low- and middle-income nations. ${ }^{[1]}$ Further, the worst affected regions in terms of incidence are Western Pacific and Southeast Asia, while the African region has reported maximum mortality. ${ }^{[1,2]}$ Not only that the available estimates do not reflect the precise picture as many cases often go unreported, especially nonfatal events, and even drowning deaths resulting because of suicide or homicide or disasters are excluded.$^{[2,3]}$ Moreover, it also contributes a significant financial burden on the families and on the health system. ${ }^{[2]}$

The epidemiological assessment of the global trends revealed that children in the age-group of 1-4 years have the highest incidence of drowning, while in excess of $50 \%$ of victims are $<25$ years. ${ }^{[1]}$ Moreover, the overall death rates have been twice more common in males than females owing to high-risk behaviors. ${ }^{[1]}$ In addition, factors such as poor swimming skills, easy access to open water sources either because of occupation or due to proximity to house, frequent traveling on water in boats or ships poorly maintained or manned by un-experienced drivers, flood disasters, infants left unsupervised near water, tourists unaware of prevalent risks, and lack of barriers limiting exposure to water bodies are some of the known potential risk factors. ${ }^{[1-4]}$

It is extremely important to understand that once an individual begins to drown, the result is usually fatal and is eventually determined based on the promptness of rescuing the individual from the water, and speed with which appropriate resuscitation is executed. ${ }^{[2,5]}$ Thus, prevention is extremely crucial, and interventions such as creating barriers to restrict access to open water sources; building safe places for under-five children away from water sources; and teaching basic swimming, water safety, and safe rescue-related skills in schools will have a sizeable impact on the overall burden of the problem. ${ }^{[2-4]}$ Further, measures such as training observers regarding safe rescue and resuscitation, creating awareness about the condition and susceptibility among children, establishing and enforcing safe boating regulations, ensuring preparedness to adequately respond to flood disasters, encouraging intersectoral coordination, and promoting well-designed studies to ascertain the high risk factors and impact of corrective strategies will also eventually reduce the incidence of drowning and its associated consequences..$^{[2-5]}$

Acknowledging the public health importance and the fact that the condition has been neglected till date, the World Health Organization has appealed to the national governments to prioritize the concern of drowning prevention, generate reliable date on drowning estimates, integrate it with other public health agendas, formulate a water safety plan at the national level, and even advocate for the involvement of all concerned stakeholders. ${ }^{[1,2]}$ 
To conclude, drowning is an important global public health concern with a significant impact on health standards of children and youth. As the condition is preventable, implementation of proven measures at various levels can significantly minimize the risk of drowning and associated mortality, especially in low-resource settings.

\section{Financial support and sponsorship}

Nil.

\section{Conflicts of interest}

There are no conflicts of interest.

\section{Saurabh RamBihariLal Shrivastava, Prateek Saurabh Shrivastava, Jegadeesh Ramasamy Department of Community Medicine,} Shri Sathya Sai Medical College and Research Institute, Kancheepuram, Tamil Nadu, India

Correspondence: Dr. Saurabh RamBihariLal Shrivastava, Department of Community Medicine, Shri Sathya Sai Medical College and Research Institute, $3^{\text {rd }}$ Floor, Ammapettai Village, Thiruporur - Guduvancherry Main Road, Sembakkam Post, Kancheepuram - 603 108, Tamil Nadu, India. E-mail: drshrishri2008@gmail.com

\section{References}

1. World Health Organization. Drowning - Fact Sheet No. 347; 2014.
Available from: http://www.who.int/mediacentre/factsheets/fs347/en/. [Last accessed on 2016 May 27].

2. World Health Organization. Global Report on Drowning: Preventing a Leading Killer. Geneva: World Health Organization Press; 2014. p. 1-13.

3. Shaikh MA. Epidemiology of drowning and near drowning at Karachi beaches from 2012 to 2014. J Pak Med Assoc 2016;66:602-5.

4. Hossain M, Mani KK, Sidik SM, Hayati KS, Rahman AK. Socio-demographic, environmental and caring risk factors for childhood drowning deaths in Bangladesh. BMC Pediatr 2015;15:114.

5. Mott TF, Latimer KM. Prevention and treatment of drowning. Am Fam Physician 2016;93:576-82.

This is an open access article distributed under the terms of the Creative Commons Attribution-NonCommercial-ShareAlike 3.0 License, which allows others to remix, tweak, and build upon the work non-commercially, as long as the author is credited and the new creations are licensed under the identical terms.

\begin{tabular}{|l|l|}
\hline \multicolumn{2}{|c|}{ Access this article online } \\
\hline Quick Response Code: & Website: \\
\hline & www.ijccm.org \\
\cline { 2 - 3 } & \\
\hline
\end{tabular}

How to cite this article: Shrivastava SR, Shrivastava PS, Ramasamy J. Dealing with the neglected public health issue of drowning in low-resource settings. Indian J Crit Care Med 2016;20:433-4. 